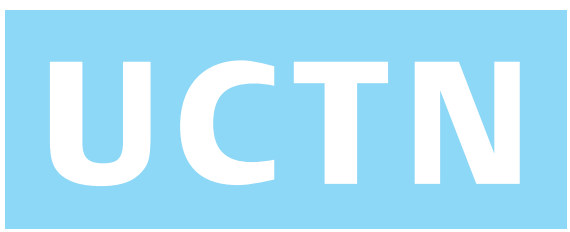

\title{
Endoscopic removal of giant Brunneroma presenting as a large pedunculated polyp
}

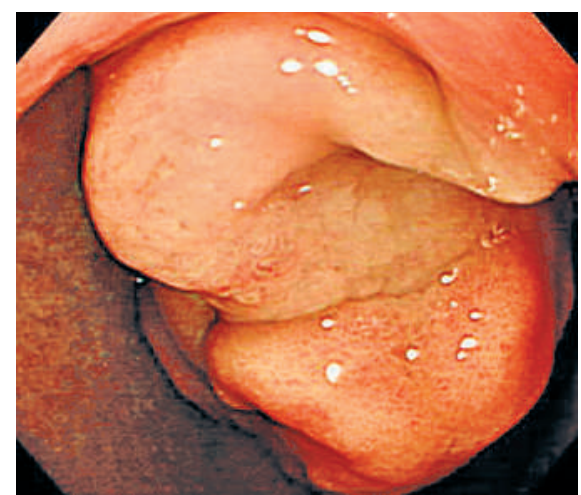

Figure 1 Endoscopic view of the Brunneroma at the posterior wall of the bulb of the duodenum.

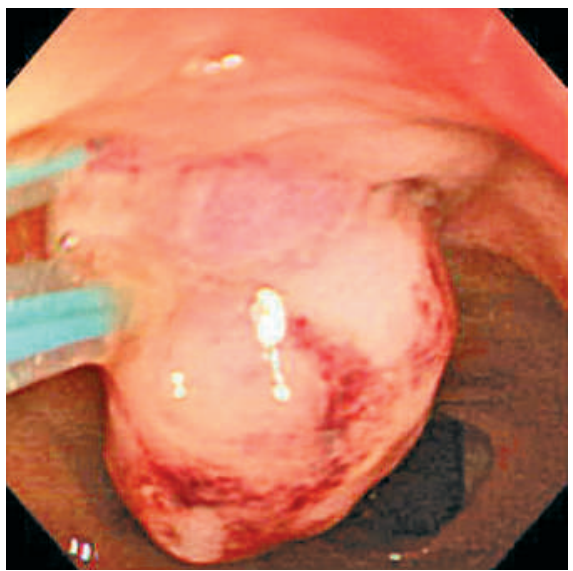

Figure 2 Stump site with no evidence of bleeding.

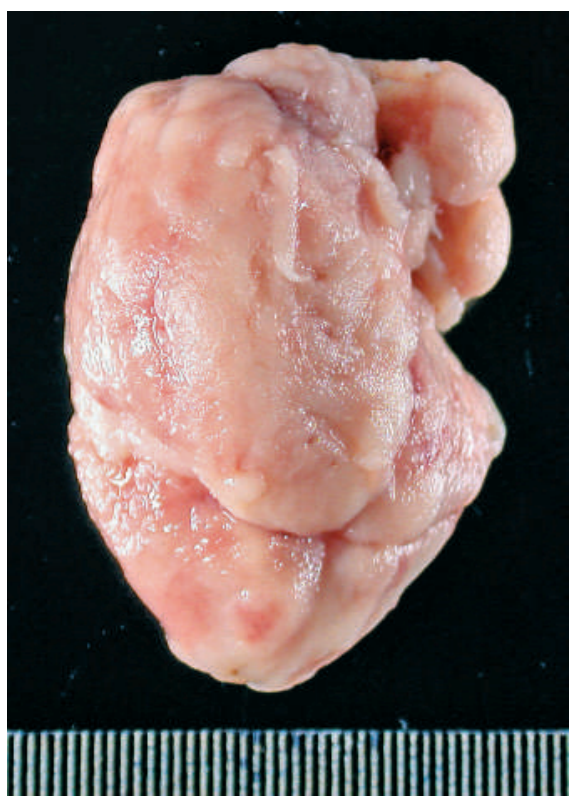

Figure 3 The resected specimen.

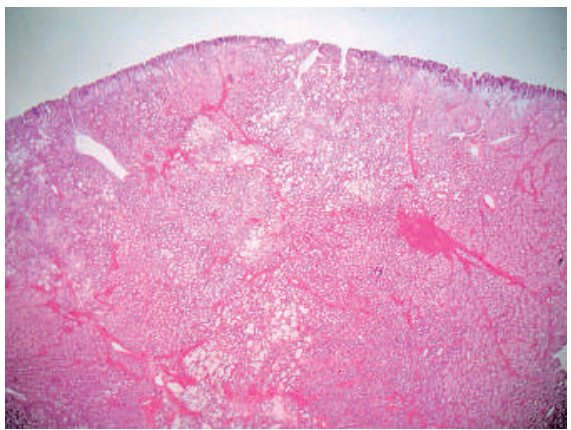

Figure 4 Histologic section of the tumor composed of hyperplastic lobules of Brunner's glands (hematoxylin and eosin [H\&E]; original magnification $\times 25$ ).

A 50-year-old man was referred to our hospital for evaluation of indigestion. The physical examination was unremarkable. Routine laboratory tests showed regular findings. Upper endoscopy revealed incidentally a huge pedunculated polyp on the posterior wall of the bulb of the duodenum (Figure 1). Endoscopic ultrasonography showed that the submucosa projected up into the 11-mm thick stalk of the polyp.

Endoscopic resection was performed. Two detachable snares were applied to the base of the stalk to prevent bleeding after polypectomy. The snare loop for severance was placed just above these two snares, while the stalk was straightened with a pair of grasping forceps which were passed through the secondary accessory channel of a double channel endoscope. The strangulated polyp was cut by electric current while its head was grasped with a basket so as not to lose the specimen. Extraction of the large polypectomized specimen through the pyloric ring and the esophagus presented a considerable challenge. The stump site was examined immediately after polypectomy for any evidence of residual lesion (Figure $\mathbf{2}$ ).

The excised tumor, measuring $3.5 \times 5 \mathrm{~cm}$, was fixed in formalin (Figure 3 ). On microscopic examination, the tumor was found to be composed of hyperplastic lobules of Brunner's glands. They were separated by intervening bands of fibrous tis- sue, adipose tissue, ducts and well developed aggregated lymphoid tissue (Figure 4). No evidence of malignancy was found in the hyperplastic Brunner's glands or in the surrounding duodenal mucosa. The patient recovered uneventfully and was discharged. Endoscopy at 6 weeks after resection showed no residual tumor.

Hyperplasia of Brunner's glands, or socalled Brunneroma, which is rarely accompanied with adenocarcinoma [1], may be excised endoscopically, even if the Brunneroma is large [2]. The endoscopist must be aware that the complication rate for polypectomy in the duodenum is higher than that for the stomach or the colon. Also the proximity of important anatomical structures should always be considered [3].

Endoscopy_UCTN_Code_CCL_1AB_2AZ_3AB

\section{Y. S. Kim¹, I. S. Jung1, G. J. Cheon' ${ }^{2}$,} J. Y. Cho' ${ }^{2}$, J. S. Lee', S. Y. Jin', C. S. Shim ${ }^{1}$ ${ }^{1}$ Institute for Digestive Research, Digestive Disease Center, SoonChunHyang University Hospital, Seoul, Korea

${ }^{2}$ Division of Gastroenterology and Hepatology, Department of Internal Medicine, Gangneung Asan Hospital, Gangwon, Korea.

\section{References}

${ }^{1}$ Akino K, Kondo Y, Ueno A et al. Carcinoma of duodenum arising from Brunner's gland. J Gastroenterol 2002; 37: 293-296

2 Bastlein C, Decking R, Voeth C, Ottenjann R. Giant Brunneroma of the duodenum. Endoscopy $1988 ; 20: 154-155$

${ }^{3}$ Khawaja HT, Deakin M, Colin-Jones DG. Endoscopic removal of a large ulcerated Brunner's gland adenoma. Endoscopy 1986; 18: $199-201$

\section{Corresponding author}

\section{S. Shim, MD}

140 - 743, Digestive Disease Center SoonChunHyang University Hospital 657 Hannam-dong, Yongsan-gu Seoul, Korea

Fax: $\quad+82-2-7099696$

Email: csshim@hosp.sch.ac.kr

DOI: $10.1055 / s-2006-945153$ 